Fournal of Medical Genetics (1971). 8, 179.

\title{
47,XX,13 + with Snodgrass Phenotype II* Are Different Chromosomes Associated with Two Clinical Varieties of D-trisomy?
}

\author{
RICHARD L. NEU, SALMA REGINA ASSEMANY, and LYTT I. GARDNER
}

From the Genetic and Endocrine Unit, Department of Pediatrics, State University of New York, Upstate Medical Center, Syracuse, New York 13210, USA

Snodgrass et al (1966) divided the D trisomy syndrome into two phenotypic categories based on facial appearance. Patients in their first category had facies associated with defects of prosencephalic cleavage. A striking finding was median cleft lip and palate. In addition there was orbital hypotelorism with severe ocular anomalies, hypoplasia or aplasia of the crista galli, of the median philtrum, and of other parts of the ethnoid bone and the nasal septum. According to these authors, this malformation complex is due to the aberrant development of the embryonic median fronto-nasal process.

In the second category of Snodgrass et al, the facies did not exhibit the prosencephalic type of defect. These patients closely resemble each other and bear little resemblance to category I patients. They show mild microcephaly and micrognathia. The nose is large, with a broad ridge and bulbous tip. There are redundant skin folds in the mandibular and periorbital regions. The mouth may be large and turned down. There are no severe optic defects; cleft lip and palate are not usually observed.

We have had the opportunity to do an autoradiographic study on an infant girl with category II D trisomy (Fig. 1). The extra chromosome in this case appears to be a $\mathrm{D}_{1}$ (Fig. 2).

\section{Comment}

Yunis, Hook, and Mayer (1964) proposed that the $\mathrm{D}$ group chromosome with late replication in the distal portion of the long arm be designated as $D_{1}$. The $\mathrm{D}_{2}$ chromosomes in the metaphase were more heavily labelled in the proximal portion, and the $D_{3}$ chromosomes were the most lightly labelled in the $D$

Received 18 May 1970.

- This study was aided by research grant AM-02504 from the National Institute of Arthritis and Metabolic Diseases, United States Public Health Service.

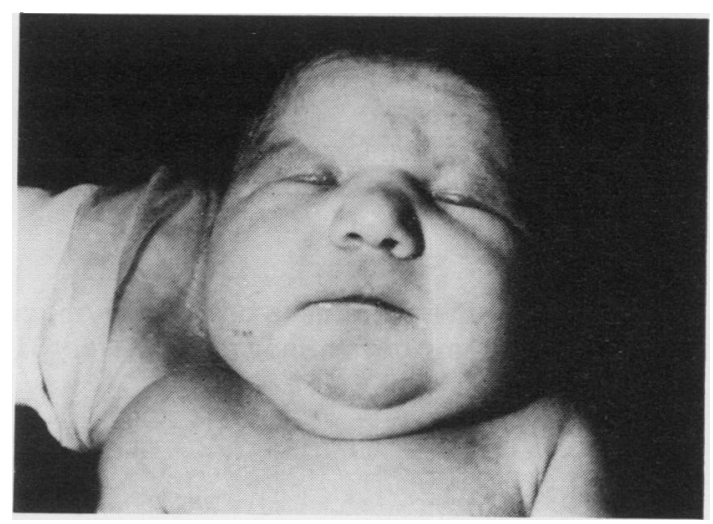

Fig. 1. The patient's face at age 1 week, showing lack of prosencephalic defects (phenotypic category II).

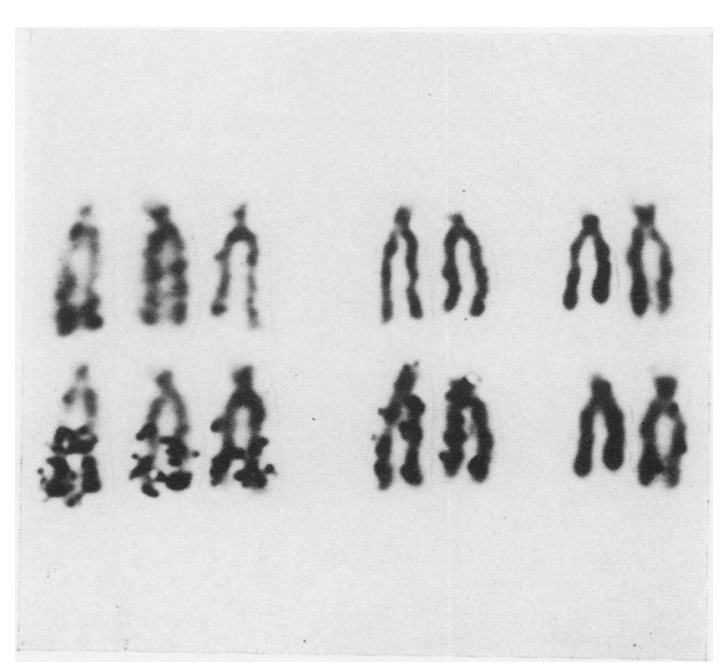

Fig. 2. Labelled D group chromosomes from the patient in Fig. 1 showing the extra chromosome to be a $D_{1}$. 
group. Autoradiographic evidence was also presented by these authors that the extra chromosome in a case of phenotypic category II D-trisomy was a $\mathrm{D}_{1}$ chromosome.

Other studies have also indicated that a $D_{1}$ chromosome is the extra one in D trisomy (Büchner, Pfeiffer, and Stupperich, 1965; Giannelli, 1965; Giannelli and Howlett, 1966). Allderdice and Miller (1968), however, reported a D trisomy patient whose extra $\mathrm{D}$ chromosome labelled more heavily in the proximal portion, indicating it was a $\mathrm{D}_{2}$. Clinical descriptions of the patients were not given in the last four references, so it is not clear whether these patients fit into phenotype category I or II.

Based on these findings it occurred to us that the two clinical categories of $D$ trisomy might involve two different $D$ group chromosomes, $D_{1}$ and $D_{2}$. Further autoradiographic studies on $\mathrm{D}$ trisomy patients from both phenotypic categories I and II would help resolve this question.

\section{Summary}

Autoradiographic studies have been made on an infant with_D trisomy of the Snodgrass category II phenotype. The results indicated that the trisomy was associated with a $D_{1}$ chromosome. This suggests the possibility that $\mathrm{D}$ trisomy of the phenotype I category may involve other chromosomes of the D group.

We are indebted to Miss Saddie King for technical assistance.

REFERENCES

Allderdice, P. W. and Miller, O. J. (1968). Identification of chromosomes 13, 14 and 15 in man by DNA replication pattern. Abstracts, Seventh Conference, Mammalian Cytology and Somatic Cell Genetics, Gatlinburg, Tennessee, October 23-26.

Büchner, T., Pfeiffer, R. A., and Stupperich, E. (1965). Reduplikationsverhalten der Chromosomen der Gruppe D (13-15) und Identifikation des Extrachromosoms bei Trisomie D. Klinische Wochenschrift, 43, 1062-1064.

Giannelli, F. (1965). Autoradiographic identification of the D (1315) chromosome responsible for $D_{1}$ trisomic Patau's syndrome. Nature (London), 208, 669-672.

Giannelli, F. and Howlett, R. M. (1966). The indentification of the chromosomes of the D group (13-15) Denver: an autoradiographic and measurement study. Cytogenetics, 5, 186-205.

Snodgrass, G. J. A. I., Butler, L. J., France, N. E., Crome, L., and Russell, A. (1966). The 'D' (13-15) trisomy syndrome: an analysis of 7 examples. Archives of Disease in Childhood, 41, 250-261.

Yunis, J. J., Hook, E. B., and Mayer, M. (1964). Deoxyribonucleic acid replication pattern of trisomy $D_{1}$. Lancet, 2, 935-937. 